\title{
Oxidative Stress and Pathogenesis in Malaria
}

\author{
Marilyn Vasquez, Marisol Zuniga and Ana Rodriguez* \\ Department of Microbiology, New York University Grossman School of Medicine, New York, NY, United States
}

OPEN ACCESS

Edited by:

Rubem Figueiredo Sadok Menna-Barreto,

Oswaldo Cruz Foundation (Fiocruz),

Brazil

Reviewed by:

Tracey Lamb,

The University of Utah, United States

Chiranjib Pal,

West Bengal State University, India

*Correspondence:

Ana Rodriguez

Ana.rodriguez@nyumc.org

Specialty section:

This article was submitted to

Parasite and Host,

a section of the journal

Frontiers in Cellular and

Infection Microbiology

Received: 31 August 2021 Accepted: 16 November 2021

Published: 30 November 2021

Citation:

Vasquez M, Zuniga M and Rodriguez $A$

(2021) Oxidative Stress and

Pathogenesis in Malaria.

Front. Cell. Infect. Microbiol. 11:768182.

doi: 10.3389/fcimb.2021.768182
Malaria is a highly inflammatory and oxidative disease. The production of reactive oxygen species by host phagocytes is an essential component of the host response to Plasmodium infection. Moreover, host oxidative enzymes, such as xanthine oxidase, are upregulated in malaria patients. Although increased production of reactive oxygen species contributes to the clearance of the parasite, excessive amounts of these free radicals can mediate inflammation and cause extensive damage to host cells and tissues, probably contributing to severe pathologies. Plasmodium has a variety of antioxidant enzymes that allow it to survive amidst this oxidative onslaught. However, parasitic degradation of hemoglobin within the infected red blood cell generates free heme, which is released at the end of the replication cycle, further aggravating the oxidative burden on the host and possibly contributing to the severity of life-threatening malarial complications. Additionally, the highly inflammatory response to malaria contributes to exacerbate the oxidative response. In this review, we discuss host and parasite-derived sources of oxidative stress that may promote severe disease in $P$. falciparum infection. Therapeutics that restore and maintain oxidative balance in malaria patients may be useful in preventing lethal complications of this disease.

Keywords: malaria, Plasmodium falciparum, Plasmodium vivax, oxidative stress, reactive oxygen species, oxidation, pathogenesis, cerebral malaria

\section{INTRODUCTION}

Oxidative stress is caused by reactive oxygen or nitrogen atoms that have unpaired electrons in their outer shell. They are called reactive oxygen species (ROS) or reactive nitrogen species (RNS) and are commonly produced in cells. These radicals are oxidants that can damage cellular components, but are also involved in essential cellular processes, such as intracellular signaling and the oxidative burst in innate immune cells (Liguori et al., 2018).

Oxidative stress has been related to aging and to a variety of diseases including diabetes, cancer and cardiovascular complications, based on a general hypothesis that molecular damages induced by ROS and RNS result in the functional impairments that underlie aging and the aforementioned diseases (Liguori et al., 2018). However, the role of oxidative stress in infectious diseases is more complex, since it contributes to the elimination of invading pathogens, but also causes molecular damage in the host. It is well known that infections frequently induce high levels of ROS and RNS that are formed as part of the inflammatory response, and also as a consequence of organ damage and metabolic changes induced by infection (Pohanka, 2013). 
There is a tight relation between inflammation and oxidative stress during any infection (Nathan and Cunningham-Bussel, 2013). It is well known that innate immune cells recognize pathogens and respond by triggering strong inflammatory responses. Innate immune cells phagocytose these pathogens and attempt to eliminate them by rapidly increasing the production of ROS in their phagosomes in a mechanism called oxidative or respiratory burst. ROS produced during the oxidative burst are also released extracellularly, contributing to the increase of the oxidative state in the infected host (Thomas, 2017). Inflammatory and oxidative pathways are linked in immune cells through the transcription factor NF-kB, which is activated by inflammatory mediators and, in turn, can activate pro-oxidant genes in these cells (Lingappan, 2018).

Conversely, oxidative stress can induce inflammation, since ROS regulate the inflammatory response in immune cells through the activation of NF-kB, which results in the secretion of inflammatory cytokines (Lingappan, 2018). ROS also serves as the first signal for the activation of the inflammasome (Ty et al., 2019), further contributing to the inflammatory response.

Malaria is a highly inflammatory and oxidative disease. During the blood stage of infection, the level of oxidative stress in plasma is frequently measured by determining the concentration of malondialdehyde (MDA), a lipid peroxide which is formed as a consequence of oxidation of unsaturated lipids and reflects the levels of free radicals in the circulation (Ayala et al., 2014). This method has allowed for the determination of the levels of oxidative stress in plasma samples from malaria patients. Results indicate that oxidative stress is higher in malaria patients, caused by either Plasmodium falciparum or P. vivax infection, compared to healthy controls (Das and Nanda, 1999; Pabon et al., 2003; Yazar et al., 2004; Prasannachandra et al., 2006; Tiyong Ifoue et al., 2009; Bilgin et al., 2012; Narsaria et al., 2012). Additionally, high levels of oxidative stress were found in monkeys infected with P. knowlesi
(Srivastava et al., 1992) and mice infected with $P$. berghei, $P$. yoelii or P. chabaudi (Nneji et al., 2013; Scaccabarozzi et al., 2018), indicating that oxidative stress is a generalized phenomenon in Plasmodium infections.

The increase in oxidative stress observed in malaria patients infected with either $P$. falciparum or $P$. vivax infections is often coupled with a decrease of anti-oxidant levels (Table 1). This decrease in both enzymatic and non-enzymatic antioxidants during malaria evidences the loss of the homeostatic balance between free radicals and antioxidant capacity that is maintained in healthy tissues.

During the blood stage of Plasmodium infection, a relation between oxidative stress and inflammation is evidenced by ROSinduced activation of macrophages (Ty et al., 2019) and dendritic cells (Gotz et al., 2019), which results in the secretion of inflammatory cytokines. Studies in vitro showed that ROS not only activates classical cytokine secretion in these cells, but also provided a first essential signal necessary for inflammasome activation, with the parasite $P$. falciparum providing the second one (Ty et al., 2019). Plasmodium infections in mice show a gradual increase in both inflammatory cytokines and oxidative stress in different organs (Gosavi et al., 2016). In P. falciparum patients, the fact that cytokine levels and oxidative stress both increase with disease severity (Abdullahi et al., 2020), and the finding of a direct correlation between inflammatory cytokines and ROS levels in patient plasma, suggest a link between inflammation and oxidative stress in malaria (Ty et al., 2019).

During the initial liver stage of malaria, the parasite is susceptible to oxidative stress which decreases parasite survival within the hepatocytes. Interestingly, a high-fat diet which increased the levels of oxidative stress was found to be highly protective of liver stage malaria infection (Zuzarte-Luis et al., 2017). Conversely, high levels of heme-oxygenase-1 (HO-1), which has a strong antioxidant activity, promote Plasmodium liver infection (Epiphanio et al., 2008). Since HO-1 is part of the

TABLE 1 | Malaria patients have significantly increased lipid peroxidation and decreased levels of antioxidants.

\begin{tabular}{|c|c|c|c|}
\hline Plasmodium species & Lipid peroxidation & Antioxidants & Study \\
\hline P. falciparum & $\uparrow$ & $\begin{array}{l}\downarrow \text { Catalase } \\
\downarrow \text { Glutathione } \\
\downarrow \text { Tocopherol } \\
\downarrow \text { Ascorbate }\end{array}$ & (Das and Nanda, 1999) \\
\hline P. vivax & $\uparrow$ & $\begin{array}{l}\downarrow \text { Catalase } \\
\downarrow \text { Glutathione } \\
\downarrow \text { Superoxide dismutase } \\
\downarrow \text { Glutathione peroxidase } \\
\downarrow \text { Ascorbate } \\
\downarrow \text { Vitamin A }\end{array}$ & (Erel et al., 1997) \\
\hline $\begin{array}{l}\text { P. falciparum } \\
\& \text { P. vivax }\end{array}$ & $\uparrow$ & $\downarrow$ Tocopherol & (Prasannachandra et al., 2006) \\
\hline $\begin{array}{l}\text { P. falciparum \& P. vivax } \\
P . \text { falciparum }\end{array}$ & $\uparrow$ & $\begin{array}{l}\downarrow \text { Catalase } \\
\downarrow \text { Vitamin E } \\
\downarrow \text { Vitamin A }\end{array}$ & $\begin{array}{l}\text { (Pabon et al., 2003) } \\
\text { (Delmas-Beauvieux et al., 1995) }\end{array}$ \\
\hline P. vivax & $\uparrow$ & $\begin{array}{l}\downarrow \text { Superoxide dismutase } \\
\downarrow \text { Glutathione peroxidase }\end{array}$ & (Bilgin et al., 2012) \\
\hline P. falciparum & $\uparrow$ & $\downarrow$ Ascorbate & (Das et al., 1993) \\
\hline P. falciparum \& P. vivax & $\uparrow$ & $\begin{array}{l}\downarrow \text { Superoxide dismutase } \\
\downarrow \text { Vitamin E }\end{array}$ & (Kulkarni et al., 2003) \\
\hline
\end{tabular}


inflammatory response induced in the host by Plasmodium infection, the parasite would ultimately benefit from this response because of reduced levels of oxidative stress that would otherwise impair its growth. This constitutes a perfect example of the close relation between the inflammatory and oxidative responses during infection and the important consequences that are derived for the host.

\section{SOURCES OF OXIDATIVE STRESS DURING MALARIA}

During the blood stage of malaria, there are different sources of host-derived oxidative stress that are either a direct result of Plasmodium infection of erythrocytes, such as heme, or a consequence of the host response to infection, which includes systemic upregulation of host oxidative enzymes and the phagocytic oxidative burst (Figure 1). Additionally, anti-malarial treatments are frequently contribute to oxidative stress, since their mechanism of action is mediated by oxidative killing of the parasite.

\section{Heme}

Heme is a source of oxidative stress that affects both the parasite and the host during malaria. Plasmodium parasites consume hemoglobin within infected erythrocytes as a source of amino acids (Becker et al., 2004). The breakdown of hemoglobin results in the release of heme, which can produce reactive oxygen species via its iron atom. Heme iron can promote the production of the hydroxyl radical via the Fenton reaction, which can induce damage to the parasite and the host (Percario et al., 2012). To counteract the adverse effects of heme, Plasmodium converts heme into hemozoin, an intracellular aggregate where heme molecules are interlinked, forming a crystal structure. Hemozoin does not induce oxidative damage to the host or parasite.

However, previous reports observed that not all heme molecules are successfully crystallized into hemozoin within the infected erythrocyte (Becker et al., 2004), meaning that free heme that has not been converted to hemozoin can cause damage to host cells and tissues once it has been released. Heme can also be released via hemolysis of uninfected red blood cells, which also occurs during Plasmodium infection (Haldar and Mohandas, 2009). Therefore, lysis of both infected and uninfected erythrocytes are potential contributors to oxidative stress in malaria.

\section{Xanthine Oxidase}

Another source of oxidative stress during Plasmodium infection is the host oxidative enzyme xanthine oxidase $(\mathrm{XO})$. $\mathrm{XO}$ generates reactive oxygen species such as superoxide $\left(\mathrm{O}_{2 \cdot-}\right)$ and hydrogen peroxide $\left(\mathrm{H}_{2} \mathrm{O}_{2}\right)$ as it breaks down hypoxanthine to xanthine and

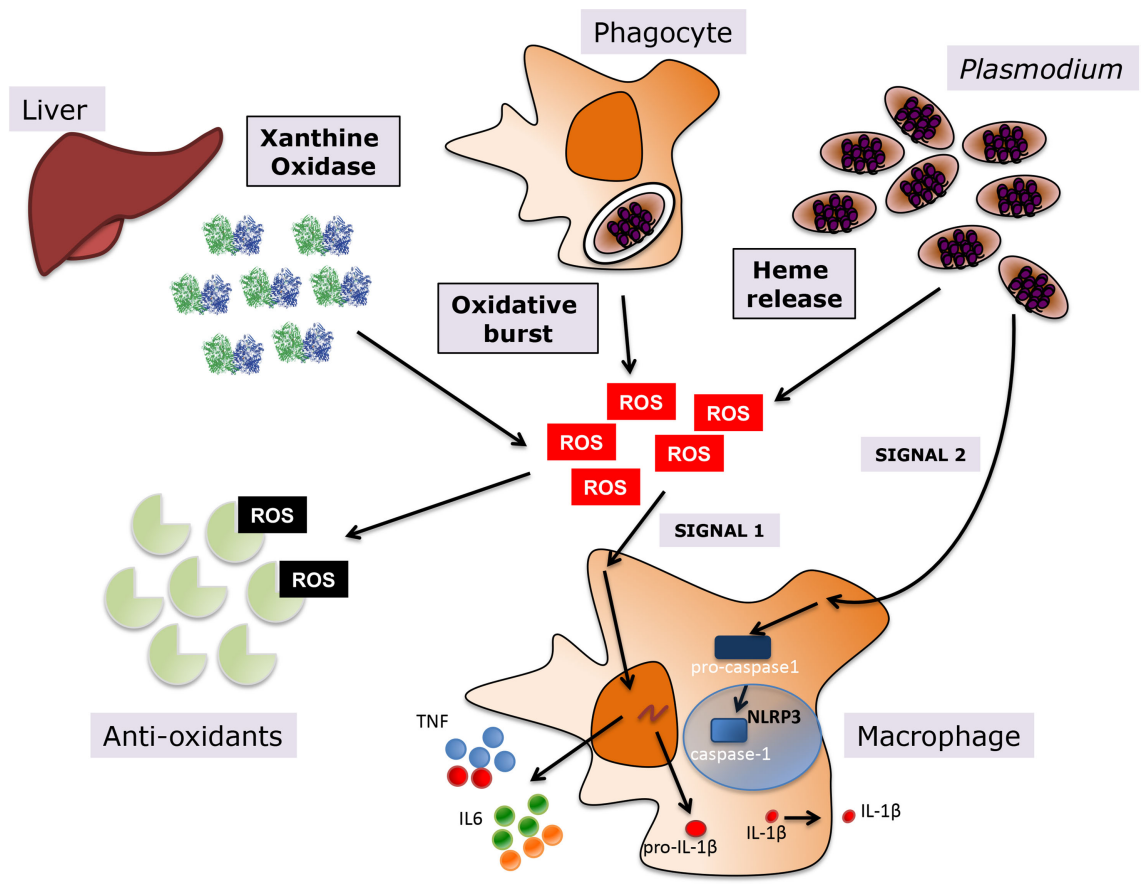

FIGURE 1 | Oxidative stress during Plasmodium infection. Various sources contribute to the oxidative environment during malaria, including upregulation of host enzymes such as $\mathrm{XO}$, the oxidative burst in macrophages upon phagocytosis of infected erythrocytes, and heme release from hemoglobin degradation in host infected erythrocytes. A balance between levels of anti-oxidants in the human host and the generation of ROS determines the levels of oxidative stress. ROS promote inflammation in malaria, leading to the activation of macrophages and the subsequent release of pro-inflammatory cytokines, such as TNF and IL6 among others, but also inflammasome-dependent IL1- $\beta$, where ROS provide priming signal 1 and $P$. falciparum the activating signal 2. 
ultimately, to uric acid (Battelli et al., 2016). Elevated levels of this enzyme have been reported in both mouse (Tubaro et al., 1980) and human infections (Iwalokun et al., 2006; Ty et al., 2019) with Plasmodium parasites. Pediatric patients with severe malaria (Iwalokun et al., 2006) and adult patients with cerebral malaria (Ty et al., 2019) have higher levels of XO in circulation compared to patients with uncomplicated malaria, supporting a pathogenic role for this enzyme in exacerbating severity of disease during Plasmodium infection. XO also contributes to inflammation in malaria, since XO-derived extracellular ROS, in combination with lysates of $P$. falciparum-infected red blood cells (iRBCs), activate monocyte-derived macrophages in vitro, leading to the production of the inflammatory cytokine IL-1 $\beta$ and chemokines IL-8, CCL5, and CCL2 (Ty et al., 2019). This enzyme also promotes maturation and cytokine secretion in dendritic cells incubated with $P$. falciparum-iRBCs (Gotz et al., 2019). Moreover, XO augmented the ability of $P$. falciparum - activated dendritic cells to induce $\mathrm{T}$ cell proliferation, contributing to both dendritic cell and $\mathrm{T}$ cell responses to Plasmodium infection (Gotz et al., 2019).

Despite its role in promoting inflammation in malaria, there are reports suggesting a protective role for $\mathrm{XO}$ in the context of Plasmodium infection. XO interferes with the growth of in vitro cultures $P$. falciparum, given that it consumes hypoxanthine, which the parasite needs to synthesize purines (Berman et al., 1991). Moreover, XO-generated ROS have also been implicated as detrimental agents for the growth of Plasmodium parasites. Cultures of $P$. yoelii that are pre-treated with $\mathrm{XO}$ and subsequently injected into mice are unable to replicate effectively within a murine host, as indicated by the lower parasitemia in these animals compared to that of other animals that were challenged with untreated $P$. yoelii. However, pre-incubation of $P$. yoelii cultures with $\mathrm{XO}$ in the presence of the antioxidant enzyme catalase restored the virulence of the parasite, indicating that XO-produced ROS interfered with its survival within the host (Dockrell and Playfair, 1984).

\section{Phagocytic Oxidative Burst}

The production of ROS is a crucial part of the host response to various infectious agents, including Plasmodium. The innate immune system of the host uses the oxidative burst to eliminate invading pathogens. This mechanism is triggered in immune cells such as neutrophils and macrophages after phagocytosis of microbial pathogens. Cells activate nicotinamide adenine dinucleotide phosphate reduced (NADPH) oxidase to produce high concentrations of ROS in the phagosome that result in the death of the microbe (Forman and Torres, 2002).

Exposure of human neutrophils and monocytes to $P$. falciparum merozoites and secreted antigens in vitro triggers the oxidative burst in these cells, leading to increased production of ROS (Kharazmi et al., 1987). While the oxidative burst is meant to curb the replication and survival of the parasite, it has also been shown that phagocytosis of Plasmodium antigens can be detrimental for the oxidative capacity of phagocytic cells, since macrophages that phagocytosed purified hemozoin had diminished NADPH oxidase activity (Schwarzer and Arese, 1996). A study conducted with neutrophils isolated from Gambian children with $P$. falciparum malaria showed that these cells have diminished oxidative burst capacity compared to neutrophils isolated from healthy controls (Cunnington et al., 2012), lending further support to the hypothesis that the oxidative burst can be compromised during Plasmodium infection. Overall, downregulation of the phagocytic oxidative burst may be beneficial in that it decreases oxidative stress for the host, but its inhibition would also facilitate the growth and survival of the parasite.

\section{Oxidative Stress Induced by Anti-Malarial Drugs}

Given that Plasmodium parasites are sensitive to ROS-mediated damage, it is not surprising that various antimalarial treatments exploit this feature of the parasite to limit its growth within human hosts. Quinolones, including chloroquine and amodiaquine, act by inhibiting the conversion of free heme to hemozoin within the infected erythrocyte, effectively increasing oxidative stress for Plasmodium parasites (Kavishe et al., 2017). Although the principal mechanism of chloroquine resistance is based on the ability of the parasites to prevent the drug from accumulating in their digestive vacuole, an increase in parasite antioxidant capacity may contribute to resistance. Notably, it has been shown the chloroquine-resistant strains of human ( $P$. falciparum) and rodent ( $P$. yoelii, and $P$. berghei) malaria have increased activity of the antioxidant enzyme glutathione-Stransferase compared to chloroquine-sensitive strains of the same species (Srivastava et al., 1999), which may help these parasites counteract the oxidative burden caused by the drug.

Another major family of anti-malarial drugs are the artemisinins, which include dihydroartemisinin and artesunate (Kavishe et al., 2017). These drugs also exert their anti-parasitic effects by increasing oxidative stress on the parasite. One of the proposed mechanisms of action for artemisinin postulates that its interaction with iron leads to the production of free radicals (Cui and Su, 2009). Notably, the antioxidant $\mathrm{N}$-acetylcysteine (NAC) can counteract the anti-parasitic effects of artesunate on $P$. falciparum, further supporting the hypothesis that these drugs act by promoting the production of free radicals that are harmful to the parasite (Arreesrisom et al., 2007).

While increasing oxidative stress is an effective mechanism of action for parasite elimination, it may also have a negative impact on the host. Artesunate-induced oxidative damage was observed in vitro in human cellular DNA (Berdelle et al., 2011) and in treated mice (Singh et al., 2015). Moreover, a study showed that malaria patients treated with anti-malarial drugs had higher levels of lipid peroxidation and lower levels of antioxidants compared to non-treated patients (Akanbi et al., 2010), suggesting that anti-malarial drugs increase oxidative stress in the host. Another report proposed using antioxidants, such as quercetin, along with chloroquine to offset the oxidative stress and toxic effects caused by this drug (Kumar Mishra et al., 2013).

\section{OXIDATIVE STRESS AND THE PATHOGENESIS OF MALARIA}

It is well documented that the levels of oxidative stress increase with severity in P. vivax (Sibmooh et al., 2004; Ray et al., 2016; 
Aqeel et al., 2021) and P. falciparum (Das and Nanda, 1999; Greve et al., 2000; Narsaria et al., 2012) infections, suggesting that oxidation may contribute to the development of complications in malaria. Although specific mechanisms have not been characterized, it is possible that ROS contributes to disease severity directly through detrimental effects of oxidative stress on the tissues or indirectly through the increase in the inflammatory response (Hemmer et al., 2005; Taoufiq et al., 2006).

It is known that oxidative stress induces lipid peroxidation in the surface of erythrocytes, reducing the deformability in these cells (Becker et al., 2004). Notably, in vitro cultures of $P$. falciparum induced lipid peroxidation of both infected and uninfected erythrocytes (Omodeo-Sale et al., 2003). In $P$. falciparum malaria patients, reduced erythrocyte deformability which was mostly observed in uninfected erythrocytes, correlated strongly with death (Dondorp et al., 1997). Since lipid peroxidation reduces erythrocyte deformability, and this has been linked to increased mortality of adults and children with malaria (Dondorp et al., 2002), it has been proposed that oxidative stress contributes to severe malaria pathogenesis through this mechanism. Possible negative consequences of erythrocyte rigidity are microcirculation obstruction and anemia caused by the increased splenic removal of uninfected rigid erythrocytes (Becker et al., 2004).

The role of oxidative stress in cerebral malaria has been studied extensively in mouse models. In mice genetically modified to express a recombinant indicator of oxidation, it was observed that oxidative stress in the brain is dependent on the development of experimental cerebral malaria (Imai et al., 2014). A positive effect of antioxidant treatments in protection of mice from the development of cerebral malaria and cognitive impairments indicates a role for oxidative stress in the pathogenesis of this complication (Thumwood et al., 1989; Kremsner et al., 1991; Reis et al., 2010; Imai et al., 2014; Nyariki et al., 2019). However, mice deficient in the production of ROS by NADPH oxidase, a key oxidative enzyme involved in the phagocytic burst, developed cerebral malaria at similar rate as wild-type mice (Sanni et al., 1999). This lack of difference in the development of pathology may reflect that there are different factors contributing to oxidative stress in the host. The knockout of one enzyme is probably not sufficient to reduce significantly the overall oxidative burden that the host faces during infection.

The role of heme-induced oxidative stress in malaria pathogenesis has been validated in different in vivo studies using knockout mice lacking the gene for HO-1. HO-1 breaks down heme into biliverdin and carbon monoxide (CO), which are antioxidants (Silva et al., 2020), and iron, which can be bound by the iron-binding protein ferritin (Balla et al., 2005). Expression of HO-1 in the context of Plasmodium infection is important in the prevention of cerebral malaria in mice (Pamplona et al., 2007). In this study, BALB/c mice challenged with $P$. berghei increased expression of HO-1 at the mRNA and protein levels and did not develop experimental cerebral malaria. On the other hand, C57BL/6 mice did develop cerebral malaria upon challenge with $P$. berghei, but they did not increase expression of HO-1. Notably, treatment of the infected C57BL/ 6 mice with cobalt protoporphyrin (CoPPIX), a HO-1 inducer, increased survival and prevented damage to the blood brain barrier (Pamplona et al., 2007). HO-1 expression is also involved in protection against acute kidney injury (Ramos et al., 2019) and acute lung injury (Pereira et al., 2016) that occur in mice during Plasmodium infection, indicating that heme may play a role in mediating various malarial complications.

Analysis of oxidative stress in brain histology of patients who died of cerebral malaria showed that $\mathrm{HO}-1$ was predominantly found in the vicinity of vessels and hemorrhages. However a similar pattern was also found in patients who died of other causes, suggesting that the proximity of HO-1 to vessels and hemorrhages may be a consequence, rather than a cause of the hemorrhage. In general, there was no pattern of widespread irreversible cell damage found in these patients, which suggests that oxidative stress is not causing generalized damage to the brain (Medana et al., 2001).

However, studies in patients suggest that heme may play an important role in different malaria complications. A study measuring plasma levels of free heme and hemopexin (a molecule that binds to heme facilitating its degradation) found that the ratio of heme to hemopexin was strongly associated with different malaria complications, including severe anemia, respiratory distress and acute kidney damage, as well as mortality after 6 months (Elphinstone et al., 2016). Additional studies in patients show that the levels of cell free hemoglobin and lipid peroxidation (an indicator of oxidative stress) are associated with acute kidney injury (Plewes et al., 2017), further suggesting a detrimental role of heme-induced oxidation in kidney function. Furthermore, adjunctive treatment with acetaminophen, which inhibits lipid peroxidation induced by free heme, resulted in decreased kidney damage in malaria patients (Plewes et al., 2018). Taken together, these results indicate an important role for heme-induced oxidation in malaria pathogenesis and open a promising path for adjunctive treatment.

It is possible that oxidative stress contributes to infected erythrocyte sequestration in the brain microvasculature by inducing increased expression of endothelial adhesion molecules such as ICAM-1 and CD36 (Becker et al., 2004). This effect may be direct, with oxidative stress potentiating the expression of adhesive receptors (Terada, 2002) or indirect, through the increase in cytokine levels, such as TNF, that strongly increase the expression of adhesive receptors.

It has also been proposed that oxidative stress may promote malaria-induced thrombocytopenia, since there was a negative correlation between the number of platelets and levels of lipid peroxidation in malaria patients (Erel et al., 2001; Araujo et al., 2008).

Several clinical trials have been performed to test the efficacy of the antioxidant $\mathrm{N}$-Acetylcysteine (NAC) as an adjunctive treatment for severe malaria. A pilot study found that NAC induced a faster normalization of lactate levels [an predictor of severity and death (White et al., 1985)] in patients with severe malaria compared to the placebo (Watt et al., 2002), supporting its potential use as an adjunctive treatment for severe malaria patients. However, larger 
studies showed no improvements in clinical outcomes (Treeprasertsuk et al., 2003; Charunwatthana et al., 2009). It was observed that NAC-treated patients presented with significantly higher levels of parasitemia, which was probably a consequence of a major antagonistic effect of NAC on the antimalarial activity of artesunate, which was being used to treat these patients (Charunwatthana et al., 2009). However, NAC adjunctive treatment had no effect in the levels of oxidative stress detected in treated patients compared to untreated controls, suggesting that this treatment was not effective at decreasing the levels of oxidative stress in patients (Charunwatthana et al., 2009).

Human clinical trials using the antioxidant pentoxifylline as adjunctive treatment for cerebral malaria showed conflicting results ranging from a significant decrease in shortening of comma resolution time and death (Das et al., 2003), to small marginally significant effects (Di Perri et al., 1995), to no effect with a non-significant increase of death in the pentoxifyllinetreated group (Lell et al., 2010). Attempts to decrease oxidation during malaria by administering vitamin $\mathrm{C}$, which has antioxidative properties, did not result in any measurable changes in cytokine levels or improvement in anemia in $P$. vivax patients (Zen Rahfiludin and Ginandjar, 2013).

In general, the disappointing results of some of the antioxidants in malaria clinical trials may be due to the inability of these treatments to significantly decrease oxidative stress in patients. Since the only trial that measured the levels of oxidative stress in treated patients found no effects in their oxidation levels (Charunwatthana et al., 2009), it remains unknown whether systemically decreasing the levels of oxidative stress in patients would have a beneficial effect in pathogenesis.

\section{DISCUSSION}

The precise role and the mechanisms of oxidative stress in malaria pathogenesis are still not well defined. On one hand, there is abundant evidence of strong correlations between levels of oxidative stress in malaria patients and disease severity in general disease severity or specific complications. Together with multiple studies in mice treated with antioxidants, the data

\section{REFERENCES}

Abdullahi, I. N., Musa, S., Emeribe, A. U., Muhammed, M., Mustapha, J. O., Shuwa, H. A., et al. (2020). Immunological and Anti-Oxidant Profiles of Malarial Children in Abuja, Nigeria. BioMedicine 11 (1), 41-50. doi: 10.37796/ 2211-8039.1010

Akanbi, O. M., Odaibo, A. B., and Ademowo, O. G. (2010). Effect of Antimalarial Drugs and Malaria Infection on Oxidative Stress in Pregnant Women. Afr. J. Reprod. Health 14 (3), 209-212. doi: 10.4314/AJRH.V14I3

Aqeel, S., Naheda, A., Raza, A., and Khan, W. (2021). Biomarkers of Disease Severity in Vivax Malaria. Parasitol. Res. 120 (4), 1437-1446. doi: 10.1007/ s00436-021-07065-3

Araujo, C. F., Lacerda, M. V., Abdalla, D. S., and Lima, E. S. (2008). The Role of Platelet and Plasma Markers of Antioxidant Status and Oxidative Stress in Thrombocytopenia Among Patients With Vivax Malaria. Mem. Inst. Oswaldo Cruz 103 (6), 517-521. doi: 10.1590/S0074-02762008000600001

Arreesrisom, P., Dondorp, A. M., Looareesuwan, S., and Udomsangpetch, R. (2007). Suppressive Effects of the Anti-Oxidant N-Acetylcysteine on the Anti- suggest that oxidative stress is a major contributor to malaria pathogenesis. On the other hand, despite multiple proposed mechanisms, there is no specific demonstrated causal link between oxidative stress and pathogenesis in human malaria.

Clinical trials with antioxidant treatments could provide a causal relation between oxidative stress and malaria pathogenesis in patients. However, it is unclear whether the anti-oxidative treatments used in the trials actually reduced oxidative stress in the patients, leaving unanswered the question of antioxidants efficacy as adjunctive treatment for severe malaria.

There is a need for mechanistic studies that can dissect the effects of oxidative stress in specific pathogenic mechanisms during malaria. Additionally, the relation between inflammation and oxidative stress, two fundamental players in the pathogenesis of infection, is still not fully understood.

Overall, maintaining oxidative balance in the host in the context of Plasmodium infection may be beneficial as it could prevent the development of pathologic complications. However, since the oxidative burst in phagocytes and anti-malarial treatments mechanism of action is mediated by inducing oxidative killing of the parasite, the possible interference of antioxidant treatments with parasite elimination must be carefully analyzed before treatment.

\section{AUTHOR CONTRIBUTIONS}

$\mathrm{MV}, \mathrm{MZ}$, and AR wrote the manuscript. All authors contributed to the article and approved the submitted version.

\section{FUNDING}

MV, MZ, and AR are supported by NIH grants 1R01NS105910 and 1R01HL150145.

\section{ACKNOWLEDGMENTS}

The authors thank Maureen Ty for help with the figure.

Malarial Activity of Artesunate. Parasitol. Int. 56 (3), 221-226. doi: 10.1016/ j.parint.2007.04.004

Ayala, A., Munoz, M. F., and Arguelles, S. (2014). Lipid Peroxidation: Production, Metabolism, and Signaling Mechanisms of Malondialdehyde and 4-Hydroxy2-Nonenal. Oxid. Med. Cell Longev. 2014, 360438. doi: 10.1155/2014/360438

Balla, J., Vercellotti, G. M., Jeney, V., Yachie, A., Varga, Z., Eaton, J. W., et al. (2005). Heme, Heme Oxygenase and Ferritin in Vascular Endothelial Cell Injury. Mol. Nutr. Food Res. 49 (11), 1030-1043. doi: 10.1002/mnfr.200500076

Battelli, M. G., Polito, L., Bortolotti, M., and Bolognesi, A. (2016). Xanthine Oxidoreductase-Derived Reactive Species: Physiological and Pathological Effects. Oxid. Med. Cell Longev. 2016, 3527579. doi: 10.1155/2016/3527579

Becker, K., Tilley, L., Vennerstrom, J. L., Roberts, D., Rogerson, S., and Ginsburg, H. (2004). Oxidative Stress in Malaria Parasite-Infected Erythrocytes: Host-Parasite Interactions. Int. J. Parasitol. 34 (2), 163-189. doi: 10.1016/j.ijpara.2003.09.011

Berdelle, N., Nikolova, T., Quiros, S., Efferth, T., and Kaina, B. (2011). Artesunate Induces Oxidative DNA Damage, Sustained DNA Double-Strand Breaks, and the ATM/ATR Damage Response in Cancer Cells. Mol. Cancer Ther. 10 (12), 2224-2233. doi: 10.1158/1535-7163.MCT-11-0534 
Berman, P. A., Human, L., and Freese, J. A. (1991). Xanthine Oxidase Inhibits Growth of Plasmodium Falciparum in Human Erythrocytes In Vitro. J. Clin. Invest. 88 (6), 1848-1855. doi: 10.1172/JCI115506

Bilgin, R., Yalcin, M. S., Yucebilgic, G., Koltas, I. S., and Yazar, S. (2012). Oxidative Stress in Vivax Malaria. Korean J. Parasitol. 50 (4), 375-377. doi: 10.3347/ kjp.2012.50.4.375

Charunwatthana, P., Abul Faiz, M., Ruangveerayut, R., Maude, R. J., Rahman, M. R., Roberts, L. J. 2nd, et al. (2009). N-Acetylcysteine as Adjunctive Treatment in Severe Malaria: A Randomized, Double-Blinded Placebo-Controlled Clinical Trial. Crit. Care Med. 37 (2), 516-522. doi: 10.1097/CCM.0b013e3181958dfd

Cui, L., and Su, X. Z. (2009). Discovery, Mechanisms of Action and Combination Therapy of Artemisinin. Expert Rev. Anti Infect. Ther. 7 (8), 999-1013. doi: 10.1586/eri.09.68

Cunnington, A. J., Njie, M., Correa, S., Takem, E. N., Riley, E. M., and Walther, M. (2012). Prolonged Neutrophil Dysfunction After Plasmodium Falciparum Malaria Is Related to Hemolysis and Heme Oxygenase-1 Induction. J. Immunol. 189 (11), 5336-5346. doi: 10.4049/jimmunol.1201028

Das, B. K., Mishra, S., Padhi, P. K., Manish, R., Tripathy, R., Sahoo, P. K., et al. (2003). Pentoxifylline Adjunct Improves Prognosis of Human Cerebral Malaria in Adults. Trop. Med. Int. Health 8 (8), 680-684. doi: 10.1046/ j.1365-3156.2003.01087.x

Das, B. S., and Nanda, N. K. (1999). Evidence for Erythrocyte Lipid Peroxidation in Acute Falciparum Malaria. Trans. R. Soc. Trop. Med. Hyg. 93 (1), 58-62. doi: 10.1016/S0035-9203(99)90180-3

Das, B. S., Patnaik, J. K., Mohanty, S., Mishra, S. K., Mohanty, D., Satpathy, S. K., et al. (1993). Plasma Antioxidants and Lipid Peroxidation Products in Falciparum Malaria. Am. J. Trop. Med. Hyg. 49 (6), 720-725. doi: 10.4269/ajtmh.1993.49.720

Delmas-Beauvieux, M. C., Peuchant, E., Dumon, M. F., Receveur, M. C., Le Bras, M., and Clerc, M. (1995). Relationship Between Red Blood Cell Antioxidant Enzymatic System Status and Lipoperoxidation During the Acute Phase of Malaria. Clin. Biochem. 28 (2), 163-169. doi: 10.1016/0009-9120(94)00071-3

Di Perri, G., Di Perri, I. G., Monteiro, G. B., Bonora, S., Hennig, C., Cassatella, M., et al. (1995). Pentoxifylline as a Supportive Agent in the Treatment of Cerebral Malaria in Children. J. Infect. Dis. 171 (5), 1317-1322. doi: 10.1093/infdis/171.5.1317

Dockrell, H. M., and Playfair, J. H. (1984). Killing of Plasmodium Yoelii by Enzyme-Induced Products of the Oxidative Burst. Infect. Immun. 43 (2), 451456. doi: 10.1128/iai.43.2.451-456.1984

Dondorp, A. M., Angus, B. J., Hardeman, M. R., Chotivanich, K. T., Silamut, K., Ruangveerayuth, R., et al. (1997). Prognostic Significance of Reduced Red Blood Cell Deformability in Severe Falciparum Malaria. Am. J. Trop. Med. Hyg. 57 (5), 507-511. doi: 10.4269/ajtmh.1997.57.507

Dondorp, A. M., Nyanoti, M., Kager, P. A., Mithwani, S., Vreeken, J., and Marsh, K. (2002). The Role of Reduced Red Cell Deformability in the Pathogenesis of Severe Falciparum Malaria and its Restoration by Blood Transfusion. Trans. $R$. Soc. Trop. Med. Hyg. 96 (3), 282-286. doi: 10.1016/S0035-9203(02)90100-8

Elphinstone, R. E., Conroy, A. L., Hawkes, M., Hermann, L., Namasopo, S., Warren, H. S., et al. (2016). Alterations in Systemic Extracellular Heme and Hemopexin Are Associated With Adverse Clinical Outcomes in Ugandan Children With Severe Malaria. J. Infect. Dis. 214 (8), 1268-1275. doi: 10.1093/infdis/jiw357

Epiphanio, S., Mikolajczak, S. A., Goncalves, L. A., Pamplona, A., Portugal, S., Albuquerque, S., et al. (2008). Heme Oxygenase-1 Is an Anti-Inflammatory Host Factor That Promotes Murine Plasmodium Liver Infection. Cell Host Microbe 3 (5), 331-338. doi: 10.1016/j.chom.2008.04.003

Erel, O., Kocyigit, A., Avci, S., Aktepe, N., and Bulut, V. (1997). Oxidative Stress and Antioxidative Status of Plasma and Erythrocytes in Patients With Vivax Malaria. Clin. Biochem. 30 (8), 631-639. doi: 10.1016/S0009-9120(97)00119-7

Erel, O., Vural, H., Aksoy, N., Aslan, G., and Ulukanligil, M. (2001). Oxidative Stress of Platelets and Thrombocytopenia in Patients With Vivax Malaria. Clin. Biochem. 34 (4), 341-344. doi: 10.1016/S0009-9120(01)00221-1

Forman, H. J., and Torres, M. (2002). Reactive Oxygen Species and Cell Signaling: Respiratory Burst in Macrophage Signaling. Am. J. Respir. Crit. Care Med. 166 (12 Pt 2), S4-S8. doi: 10.1164/rccm.2206007

Gosavi, R., Samruddhi, M., Rajopadhye, S., Ramaiya, M., Chowdhary, A., and Deshmukh, R. (2016). Influence of MDA and Pro-Inflammatory Cytokine Levels in the Pathogenesis of Severe Malaria in Experimental Murine Model. Scholars Acad. J. Biosci. 4 (8), 617-626. doi: 10.21276/sajb.2016.4.8.4

Gotz, A., Ty, M. C., and Rodriguez, A. (2019). Oxidative Stress Enhances Dendritic Cell Responses to Plasmodium Falciparum. Immunohorizons 3 (11), 511-518. doi: 10.4049/immunohorizons.1900076
Greve, B., Kremsner, P. G., Lell, B., Luckner, D., and Schmid, D. (2000). Malarial Anaemia in African Children Associated With High Oxygen-Radical Production. Lancet 355 (9197), 40-41. doi: 10.1016/S0140-6736(99)04761-3

Haldar, K., and Mohandas, N. (2009). Malaria, Erythrocytic Infection, and Anemia. Hematol. Am. Soc. Hematol. Educ. Program 2009 (1), 87-93. doi: 10.1182/asheducation-2009.1.87

Hemmer, C. J., Lehr, H. A., Westphal, K., Unverricht, M., Kratzius, M., and Reisinger, E. C. (2005). Plasmodium Falciparum Malaria: Reduction of Endothelial Cell Apoptosis In Vitro. Infect. Immun. 73 (3), 1764-1770. doi: 10.1128/IAI.73.3.1764-1770.2005

Imai, T., Iwawaki, T., Akai, R., Suzue, K., Hirai, M., Taniguchi, T., et al. (2014). Evaluating Experimental Cerebral Malaria Using Oxidative Stress Indicator OKD48 Mice. Int. J. Parasitol. 44 (10), 681-685. doi: 10.1016/j.ijpara.2014.06.002

Iwalokun, B. A., Bamiro, S. B., and Ogunledun, A. (2006). Levels and Interactions of Plasma Xanthine Oxidase, Catalase and Liver Function Parameters in Nigerian Children With Plasmodium Falciparum Infection. APMIS 114 (12), 842-850. doi: 10.1111/j.1600-0463.2006.apm_457.x

Kavishe, R. A., Koenderink, J. B., and Alifrangis, M. (2017). Oxidative Stress in Malaria and Artemisinin Combination Therapy: Pros and Cons. FEBS J. 284 (16), 2579-2591. doi: 10.1111/febs.14097

Kharazmi, A., Jepsen, S., and Andersen, B. J. (1987). Generation of Reactive Oxygen Radicals by Human Phagocytic Cells Activated by Plasmodium Falciparum. Scand. J. Immunol. 25 (4), 335-341. doi: 10.1111/j.1365-3083.1987.tb02198.x

Kremsner, P. G., Grundmann, H., Neifer, S., Sliwa, K., Sahlmuller, G., Hegenscheid, B., et al. (1991). Pentoxifylline Prevents Murine Cerebral Malaria. J. Infect. Dis. 164 (3), 605-608. doi: 10.1093/infdis/164.3.605

Kulkarni, A. G., Suryakar, A. N., Sardeshmukh, A. S., and Rathi, D. B. (2003). Studies on Biochemical Changes With Special Reference to Oxidant and Antioxidants in Malaria Patients. Indian J. Clin. Biochem. 18 (2), 136-149. doi: 10.1007/ BF02867380

Kumar Mishra, S., Singh, P., and Rath, S. K. (2013). Protective Effect of Quercetin on Chloroquine-Induced Oxidative Stress and Hepatotoxicity in Mice. Malar. Res. Treat 2013, 141734. doi: 10.1155/2013/141734

Lell, B., Kohler, C., Wamola, B., Olola, C. H., Kivaya, E., Kokwaro, G., et al. (2010). Pentoxifylline as an Adjunct Therapy in Children With Cerebral Malaria. Malar. J. 9, 368. doi: 10.1186/1475-2875-9-368

Liguori, I., Russo, G., Curcio, F., Bulli, G., Aran, L., Della-Morte, D., et al. (2018). Oxidative Stress, Aging, and Diseases. Clin. Interv. Aging 13, 757-772. doi: 10.2147/CIA.S158513

Lingappan, K. (2018). NF-kappaB in Oxidative Stress. Curr. Opin. Toxicol. 7, 8186. doi: 10.1016/j.cotox.2017.11.002

Medana, I. M., Mai, N. T., Day, N. P., Hien, T. T., Bethell, D., Phu, N. H., et al. (2001). Cellular Stress and Injury Responses in the Brains of Adult Vietnamese Patients With Fatal Plasmodium Falciparum Malaria. Neuropathol. Appl. Neurobiol. 27 (6), 421-433. doi: 10.1046/j.0305-1846.2001.00360.x

Narsaria, N., Mohanty, C., Das, B. K., Mishra, S. P., and Prasad, R. (2012). Oxidative Stress in Children With Severe Malaria. J. Trop. Pediatr. 58 (2), $147-$ 150. doi: 10.1093/tropej/fmr043

Nathan, C., and Cunningham-Bussel, A. (2013). Beyond Oxidative Stress: An Immunologist's Guide to Reactive Oxygen Species. Nat. Rev. Immunol. 13 (5), 349-361. doi: 10.1038/nri3423

Nneji, C. M., Adaramoye, O. A., Falade, C. O., and Ademowo, O. G. (2013). Effect of Chloroquine, Methylene Blue and Artemether on Red Cell and Hepatic Antioxidant Defence System in Mice Infected With Plasmodium Yoelii Nigeriensis. Parasitol. Res. 112 (7), 2619-2625. doi: 10.1007/s00436-013-3426-Z

Nyariki, J. N., Ochola, L. A., Jillani, N. E., Nyamweya, N. O., Amwayi, P. E., Yole, D. S., et al. (2019). Oral Administration of Coenzyme Q10 Protects Mice Against Oxidative Stress and Neuro-Inflammation During Experimental Cerebral Malaria. Parasitol. Int. 71, 106-120. doi: 10.1016/j.parint.2019.04.010

Omodeo-Sale, F., Motti, A., Basilico, N., Parapini, S., Olliaro, P., and Taramelli, D. (2003). Accelerated Senescence of Human Erythrocytes Cultured With Plasmodium Falciparum. Blood 102 (2), 705-711. doi: 10.1182/blood-2002-08-2437

Pabon, A., Carmona, J., Burgos, L. C., and Blair, S. (2003). Oxidative Stress in Patients With non-Complicated Malaria. Clin. Biochem. 36 (1), 71-78. doi: 10.1016/S0009-9120(02)00423-X

Pamplona, A., Ferreira, A., Balla, J., Jeney, V., Balla, G., Epiphanio, S., et al. (2007). Heme Oxygenase-1 and Carbon Monoxide Suppress the Pathogenesis of Experimental Cerebral Malaria. Nat. Med. 13 (6), 703-710. doi: 10.1038/nm1586 
Percario, S., Moreira, D. R., Gomes, B. A., Ferreira, M. E., Goncalves, A. C., Laurindo, P. S., et al. (2012). Oxidative Stress in Malaria. Int. J. Mol. Sci. 13 (12), 16346-16372. doi: 10.3390/ijms131216346

Pereira, M. L., Ortolan, L. S., Sercundes, M. K., Debone, D., Murillo, O., Lima, F. A., et al. (2016). Association of Heme Oxygenase 1 With Lung Protection in Malaria-Associated ALI/ARDS. Mediators Inflamm. 2016, 4158698. doi: $10.1155 / 2016 / 4158698$

Plewes, K., Kingston, H. W. F., Ghose, A., Maude, R. J., Herdman, M. T., Leopold, S. J., et al. (2017). Cell-Free Hemoglobin Mediated Oxidative Stress is Associated With Acute Kidney Injury and Renal Replacement Therapy in Severe Falciparum Malaria: An Observational Study. BMC Infect. Dis. 17 (1), 313. doi: 10.1186/s12879-017-2373-1

Plewes, K., Kingston, H. W. F., Ghose, A., Wattanakul, T., Hassan, M. M. U., Haider, M. S., et al. (2018). Acetaminophen as a Renoprotective Adjunctive Treatment in Patients With Severe and Moderately Severe Falciparum Malaria: A Randomized, Controlled, Open-Label Trial. Clin. Infect. Dis. 67 (7), 991-999. doi: $10.1093 / \mathrm{cid} /$ ciy213

Pohanka, M. (2013). Role of Oxidative Stress in Infectious Diseases. A Review. Folia Microbiol. (Praha) 58 (6), 503-513. doi: 10.1007/s12223-013-0239-5

Prasannachandra, V., D'Souza,, and D'Souza, B. (2006). Comparative Study on Lipid Peroxidation and Antioxidant Vitamins E and C Infalciparum Andvivax Malaria. Indian J. Clin. Biochem. 21 (2), 103-106. doi: 10.1007/BF02912922

Ramos, S., Carlos, A. R., Sundaram, B., Jeney, V., Ribeiro, A., Gozzelino, R., et al. (2019). Renal Control of Disease Tolerance to Malaria. Proc. Natl. Acad. Sci. U.S.A. 116 (12), 5681-5686. doi: 10.1073/pnas.1822024116

Ray, S., Patel, S. K., Venkatesh, A., Bhave, A., Kumar, V., Singh, V., et al. (2016). Clinicopathological Analysis and Multipronged Quantitative Proteomics Reveal Oxidative Stress and Cytoskeletal Proteins as Possible Markers for Severe Vivax Malaria. Sci. Rep. 6, 24557. doi: 10.1038/srep24557

Reis, P. A., Comim, C. M., Hermani, F., Silva, B., Barichello, T., Portella, A. C., et al. (2010). Cognitive Dysfunction is Sustained After Rescue Therapy in Experimental Cerebral Malaria, and is Reduced by Additive Antioxidant Therapy. PloS Pathog. 6 (6), e1000963. doi: 10.1371/journal.ppat.1000963

Sanni, L. A., Fu, S., Dean, R. T., Bloomfield, G., Stocker, R., Chaudhri, G., et al. (1999). Are Reactive Oxygen Species Involved in the Pathogenesis of Murine Cerebral Malaria? J. Infect. Dis. 179 (1), 217-222. doi: 10.1086/314552

Scaccabarozzi, D., Deroost, K., Corbett, Y., Lays, N., Corsetto, P., Sale, F. O., et al. (2018). Differential Induction of Malaria Liver Pathology in Mice Infected With Plasmodium Chabaudi AS or Plasmodium Berghei NK65. Malar. J. 17 (1), 18. doi: 10.1186/s12936-017-2159-3

Schwarzer, E., and Arese, P. (1996). Phagocytosis of Malarial Pigment Hemozoin Inhibits NADPH-Oxidase Activity in Human Monocyte-Derived Macrophages. Biochim. Biophys. Acta 1316 (3), 169-175. doi: 10.1016/09254439(96)00021-X

Sibmooh, N., Yamanont, P., Krudsood, S., Leowattana, W., Brittenham, G., Looareesuwan, S., et al. (2004). Increased Fluidity and Oxidation of Malarial Lipoproteins: Relation With Severity and Induction of Endothelial Expression of Adhesion Molecules. Lipids Health Dis. 3, 15. doi: 10.1186/1476-511X-3-15

Silva, R., Travassos, L. H., Paiva, C. N., and Bozza, M. T. (2020). Heme Oxygenase1 in Protozoan Infections: A Tale of Resistance and Disease Tolerance. PloS Pathog. 16 (7), e1008599. doi: 10.1371/journal.ppat.1008599

Singh, S., Giri, A., and Giri, S. (2015). The Antimalarial Agent Artesunate Causes Sperm DNA Damage and Hepatic Antioxidant Defense in Mice. Mutat. Res. Genet. Toxicol. Environ. Mutagen 777, 1-6. doi: 10.1016/j.mrgentox.2014.11.001

Srivastava, P., Puri, S. K., Dutta, G. P., and Pandey, V. C. (1992). Status of Oxidative Stress and Antioxidant Defences During Plasmodium Knowlesi Infection and Chloroquine Treatment in Macaca Mulatta. Int. J. Parasitol. 22 (2), 243-245. doi: 10.1016/0020-7519(92)90109-X

Srivastava, P., Puri, S. K., Kamboj, K. K., and Pandey, V. C. (1999). Glutathione-STransferase Activity in Malarial Parasites. Trop. Med. Int. Health 4 (4), 251254. doi: 10.1046/j.1365-3156.1999.00387.x
Taoufiq, Z., Pino, P., Dugas, N., Conti, M., Tefit, M., Mazier, D., et al. (2006) Transient Supplementation of Superoxide Dismutase Protects Endothelial Cells Against Plasmodium Falciparum-Induced Oxidative Stress. Mol. Biochem. Parasitol. 150 (2), 166-173. doi: 10.1016/j.molbiopara.2006.07.008

Terada, L. S. (2002). Oxidative Stress and Endothelial Activation. Crit. Care Med. 30 (5 Suppl), S186-S191. doi: 10.1097/00003246-200205001-00003

Thomas, D. C. (2017). The Phagocyte Respiratory Burst: Historical Perspectives and Recent Advances. Immunol. Lett. 192, 88-96. doi: 10.1016/j.imlet.2017.08.016

Thumwood, C. M., Hunt, N. H., Cowden, W. B., and Clark, I. A. (1989). Antioxidants can Prevent Cerebral Malaria in Plasmodium Berghei-Infected Mice. Br. J. Exp. Pathol. 70 (3), 293-303.

Tiyong Ifoue, S. H., Teugwa Mofor, C., Gouado, I., Teto, G., Asonganyi, T., and Amvam Zollo, P. H. (2009). Evaluation of Oxidative Stress and Antioxidant Status of Pregnant Women Suffering From Malaria in Cameroon. Indian J. Clin. Biochem. 24 (3), 288-293. doi: 10.1007/s12291-009-0054-6

Treeprasertsuk, S., Krudsood, S., Tosukhowong, T., Maek, A. N. W., Vannaphan, S., Saengnetswang, T., et al. (2003). N-Acetylcysteine in Severe Falciparum Malaria in Thailand. Southeast Asian J. Trop. Med. Public Health 34 (1), 37-42. doi: 10.1097/CCM.0b013e3181958dfd

Tubaro, E., Lotti, B., Cavallo, G., Croce, C., and Borelli, G. (1980). Liver Xanthine Oxidase Increase in Mice in Three Patholgoical Models. A Possible Defence Mechanism. Biochem. Pharmacol. 29 (13), 1939-1943. doi: 10.1016/0006-2952 (80)90107-0

Ty, M. C., Zuniga, M., Gotz, A., Kayal, S., Sahu, P. K., Mohanty, A., et al. (2019). Malaria Inflammation by Xanthine Oxidase-Produced Reactive Oxygen Species. EMBO Mol. Med. 11 (8), e9903. doi: 10.15252/emmm.201809903

Watt, G., Jongsakul, K., and Ruangvirayuth, R. (2002). A Pilot Study of NAcetylcysteine as Adjunctive Therapy for Severe Malaria. QJM 95 (5), 285-290. doi: 10.1093/qjmed/95.5.285

White, N. J., Warrell, D. A., Looareesuwan, S., Chanthavanich, P., Phillips, R. E., and Pongpaew, P. (1985). Pathophysiological and Prognostic Significance of Cerebrospinal-Fluid Lactate in Cerebral Malaria. Lancet 1 (8432), 776-778. doi: 10.1016/s0140-6736(85)91445-x

Yazar, S., Kilic, E., Saraymen, R., and Ozbilge, H. (2004). Serum Malondialdehyde Levels in Patients Infected With Plasmodium Vivax. West Indian Med. J. 53 (3), 147-149. doi: 10.18231/j.ijcbr.2021.045

Zen Rahfiludin, M., and Ginandjar, P. (2013). The Effect of Zinc and Vitamin C Supplementation on Hemoglobin and Hematocrit Levels and Immune Response in Patients With Plasmodium Vivax Malaria. Southeast Asian J. Trop. Med. Public Health 44 (5), 733-739.

Zuzarte-Luis, V., Mello-Vieira, J., Marreiros, I. M., Liehl, P., Chora, A. F., Carret, C. K., et al. (2017). Dietary Alterations Modulate Susceptibility to Plasmodium Infection. Nat. Microbiol. 2 (12), 1600-1607. doi: 10.1038/s41564-017-0025-2

Conflict of Interest: The authors declare that the research was conducted in the absence of any commercial or financial relationships that could be construed as a potential conflict of interest.

Publisher's Note: All claims expressed in this article are solely those of the authors and do not necessarily represent those of their affiliated organizations, or those of the publisher, the editors and the reviewers. Any product that may be evaluated in this article, or claim that may be made by its manufacturer, is not guaranteed or endorsed by the publisher.

Copyright (C) 2021 Vasquez, Zuniga and Rodriguez. This is an open-access article distributed under the terms of the Creative Commons Attribution License (CC BY). The use, distribution or reproduction in other forums is permitted, provided the original author(s) and the copyright owner(s) are credited and that the original publication in this journal is cited, in accordance with accepted academic practice. No use, distribution or reproduction is permitted which does not comply with these terms. 